\title{
Salivary Gland Tumors: Randomized Study of Adjuvant Chemo-Radiotherapy versus Radiotherapy Alone
}

\author{
Tarek Shouman ${ }^{1}$, Azza Niazy Taher ${ }^{1}$, Amany Helal ${ }^{2}$, Ahmed Charaf ${ }^{1}$ \\ ${ }^{1}$ Radiotherapy Department, National Cancer Institute, Cairo University, Cairo, Egypt \\ ${ }^{2}$ Medical Oncology Department, National Cancer Institute, Cairo University, Cairo, Egypt \\ Email: Charaf79@yahoo.com
}

How to cite this paper: Shouman, T., Taher, A.N., Helal, A. and Charaf, A. (2021) Salivary Gland Tumors: Randomized Study of Adjuvant Chemo-Radiotherapy versus Radiotherapy Alone. Journal of Cancer Therapy, 12, 531-553.

https://doi.org/10.4236/jct.2021.1210045

Received: July 9, 2021

Accepted: October 15, 2021

Published: October 18, 2021

Copyright $\odot 2021$ by author(s) and Scientific Research Publishing Inc. This work is licensed under the Creative Commons Attribution International License (CC BY 4.0).

http://creativecommons.org/licenses/by/4.0/

\begin{abstract}
Objective: Concurrent chemoradiation value of the resected salivary tumor adjuvant context against regular radiation therapy alone. Design: Prospective randomized clinical trial. Patients: 48 patients were randomized to either adjuvant postoperative radiology alone versus concurrent chemoradiotherapy (weekly cisplatin $40 \mathrm{mg} / \mathrm{m}^{2}$ for 6 cycles) "with resected high-risk salivary tumors of the large and minor salivary gland". Main Outcome Measures: Recurrent locoregional Free survival, distant free survival, and overall survival. Results: Out of the 48 participants in the study 31 patients had parotid gland tumors. 23 patients received solely adjuvant radiation while 25 patients received concurrent chemoradiotherapy. In the chemoradiation group, platinum-based regimens were employed in all. The mean age in both groups was 48 years. Adenoid cystic carcinoma was the primary pathogenic form of both arms $56 \%$ (28 cases). Stage II patients were $35 \%$ and $32 \%$, stage III was $39 \%$ and $48 \%$ and stage VIa were $26 \%$ and $20 \%$ in the radiation arm and chemoradiotherapy arm respectively. 40 of 48 patients (83\%) had close or positive surgical margins and 30 of 48 patients $(62 \%)$ have a perineural invasion. Both risk variables are more or less well balanced in both arms with no statistical difference. The 2- and 4-year estimates of the locoregional recurrence-free survival rate in the chemoradiation group were $95 \%$ and $73 \%$, compared to $77.4 \%$ and $43.6 \%$ in the radiation arm respectively $(\mathrm{p}=007)$. In the two-and four-year-old chemoradiation arm distant free metastases were $100 \%$ and $59 \%$ compared to $68 \%$ and $39 \%$ respectively in the radiation arm $(\mathrm{p}=0.08)$. The overall survival estimates for 2 and 4 years were $93 \%$ and $78 \%$ respectively in the Chemoradiation Group but in the radiation-alone group were $95 \%$ and $48 \%$ respectively. The statistically significant differences were $\mathrm{p}=$ 0.009 by log-rank testing. Treatment was generally tolerated, although, in the
\end{abstract}


chemoradiation group adverse symptoms, mainly mucositis increased. Conclusions: Adding weekly cisplatin as a radiosensitizer for locally advanced stage or high-grade salivary gland cancer with adjuvant conventional radiation looks to be helpful and justifies further exploration in selected patients.

\section{Keywords}

Salivary gland Tumors, Chemoradiation, Radiosensitizer, Cisplatin, Adenoid Cystic Tumors, Mucoepidermoid

\section{Introduction}

Salivary gland tumors are a varied collection of morphologically and clinically different, diagnostic and treatment issues. These are rare tumors with an overall incidence of around 2.5 cases to $3 / 100.000$ cases annually in the Western world [1]. Malignant salivary glands account for over $0.5 \%$ of all malignancies and about $3 \%$ to $5 \%$ of all cancers of the head and neck [2]. The sex distribution is equal for salivary cancer, and in the sixth decade, the majority of instances occur [3].

For advanced cancers with high-risk features, locoregional therapy failure is prevalent despite a satisfactory surgical resection. Despite the inclusion of postoperative radiation, local control outcomes improved, but the results have remained unsatisfactory. Our study's method for overcoming radioresistance of salivary gland tumors by adding simultaneous chemoradiotherapy treatment is to improve postoperative local control outcomes.

"In a retrospective population-based cohort analysis", data from 2626 individuals diagnosed with primary tumors of the submandibular gland at the University of California-Los Angeles between 1973 and 2011 were included. Patients were treated with surgery, radiation therapy, both, or neither. Overall survival OS and disease specific survival DSS were $65 \%$ and $74 \%$ at two years, $54 \%$ and $67 \%$ at five years, and $40 \%$ and $60 \%$ at ten years, respectively, according to the analysis. In $87.4 \%$ of cases, surgery was performed, and in $57.8 \%$ of cases, radiation was administered. With Surgery alone, five years overall survival was $55 \%(\mathrm{p}$ value $=0.001)$ and disease specific survival was $51 \%(\mathrm{p}$ value $=0.001)$ while using adjuvant radiotherapy, overall survival was $97 \%$ ( $\mathrm{p}$ value $=0.34$ ) after 5 years, but disease specific survival was $34 \%$ [4].

Multi-variable research by the Dutch Head and Neck Oncology Group, local control was predicted to include clinical $\mathrm{T}$, bone invasion, site, margin of resection, and treatment. Node stage, facial nerve paralysis, and treatment all influenced regional control. The relative risk of local recurrences was 9.7 for local recurrences and 2.3 for regional recurrences when the operation is compared with surgery alone Plus postoperative radiotherapy. The stages $\mathrm{T}$ and $\mathrm{N}$ were all independently connected with distant metastases: sex, perineural invasions, histological types, and clinical skin interaction. Everything played a part in survival in age, sex, T, and PN stage, location, skin, and bone invasion. A number of 
forecast variables have been found "For local, remote metastases, and overall survival management. Postoperative radiation has been found to improve local control [5]."

In the treatment of large salivary cancers, the use of post-operative radiation treatment is well established and significant. In selected circumstances, its usage significantly increases local control. In world literature, however, "there are no data from randomized studies. The use of post-operative radiation" is supported by low level clinical data. The results are confined to retrospective reports describing better local control rates than surgical resection.

Spiro and colleagues have examined the experience of 288 patients mostly treated with surgery with parotid cancers (only 12 patients underwent postoperative radiation therapy). The repetition rates were as follows by stage: 1 ) Phase I: 7\%; 2) Stage II: 21\%—Phase III: 58\% [6].

Armstrong and colleagues used a matched-pair study to adjust for the high number of factors by comparing 46 patients treated with surgery and postoperative radiation to 46 prognostically matched patients treated with surgery alone. This study found that stage I and II malignancies treated with surgery alone had excellent outcomes. Postoperative radiation therapy increased locoregional control and survival in individuals with T3 and T4 tumors or nodal illness. When high-grade tumors were treated with postoperative radiation, there was a tendency toward better outcomes. Despite the fact that radiation improved local control, local failures occurred in $51 \%$ of stage III and IV cancers and $37 \%$ of high-grade tumors [7].

Chemotherapy effectiveness data are restricted to case reports, retrospective reviews and short Phase II studies for salivary gland cancers. Malignancies of salivary gland are not treatable once metastatic. Nevertheless, their course might be often languid, especially with lung-limited metastatic adenoid cystic carcinoma. The median survival of metastatic illness is around 3 years with adenoid cystic carcinoma. Some individuals live far longer. Systemic agents were unsatisfactory, both chemical and molecular focused therapies. The choice of concurrent systemic treatment is challenging, because of the variety of grades and histologies, compared to carcinomas from the high aerodigestive tract [8].

Two big, similarly developed Phase III clinical trials by the Radiation Therapy Oncology Group (RTOG) and European Research and Organization Treatment of Cancer (EORTC) have been carried out "in high-risk squamous cell carcinomas of both head and neck" were published in 2004, showing that cisplatin "chemotherapy with postoperative radiation has been used concurrently". The same competing cisplatin and radiation regimen was treated postoperatively in patients in these 2 studies. Both trials revealed a higher rate of local control using slightly different criteria in the experimental arm. These trials have shown that the "EORTC research" has shown a better overall survival of experiments of statistical relevance [9] [10].

The greater frequency of toxicity associated with RTOG and EORTC therapy 
is reported for improved post-operative chemoradiation [9].

Several trials in Salivary Gland Tumors have explored systematic therapy for histology with or without concomitant chemotherapy. In randomized studies, the inclusion of concomitant chemotherapy was not dealt with. It has been suggested that CAP (cyclophosphamide, Adriamycin and cisplatin) treatment should be susceptible to adenocarcinoma patients, adenoid cystic carcinomas, acinic cell carcinoma, and malignant, mixed tumors, while cisplatin, 5-FU and methotrexate can better respond to those drugs used to treat squamous cell carcinoma [11].

In Schoenfeld's study, 35 salivary gland cancer patients were subjected to retrospective surgery and adjuvant radiotherapy, which were largely treated at the Dana-Farber Cancer Institute from 2005 to 2010. Local control, progression free survival and overall survival were the major goals. Acute and chronic toxicity was the secondary endpoints. Among surviving patients, "median follow-up took 2, 3 years". The median dose of radiation was $66 \mathrm{~Gy}$, whereas concurrent chemoradiotherapy was used in 22 patients (63\%). Carboplatin and paclitaxel (n $=14.64 \%)$ were the most prevalent chemotherapy treatment. More unfavorable predictive indications have been found, such as stage T3 - T4 disease (CRT, $\mathrm{n}=$ $12.55 \%$ vs. $\mathrm{n}=4.31 \%, \mathrm{p}=1.29$ ), nodal positivity (CRT, $\mathrm{n}=8.36 \%$ vs. $\mathrm{n}=1.9$ ), positive margins ( $\mathrm{n}=13.59 \%$ vs. $\mathrm{n}=5$, and $37 \% \mathrm{n}=1.380 \%$ ). The total actuarial rate of 3 years for a patient with concurrent chemoradiotherapy was $92 \%$ local surveillance. There were five (14\%) patients with distant metastases. In $8 \%, 8 \%$, $8 \%$, and $8 \%$ ( 1 percent, every) of patients with irradiation and in $18 \%, 5 \%$, and $14 \%(4,1$ and 3$)$ of those who received concomitant chemoradiation therapy were acute grade 3, respectively. There has been no acute Grade 4 poisoning. Grade 1 xerostomia ( $n=8,23$ percent) was the most prevalent late toxicity. Postoperative radiation therapy of salivary gland cancers with a high level of local control was well tolerated. In a subgroup of patients with adverse prognostic characteristics, chemoradiotherapy has resulted in excellent local control and could be indicated in selected patients. The most likely factors of prediction in patients undergoing concurrent Chemoradiotherapy, include T3 - T4, nodal positivity and positive margins. The total actuarial local control rate for three years was 92 percent and the chemical radiation group was one failure only. In total, reported follow-up is less than 5 years and so the long-term local monitoring and survival rate is assessed [12].

24 patients with resected large salivary gland tumors were analyzed by Taventynon et al. from 1998 to 2007, 12 patients control groups were treated with postoperative concomitant chemoradiotherapy and 12 patients were treated alone with radiation after surgery. With the exception of one patient, all patients had stage III or IV illness; $83 \%$ of patients have detected near or positive surgical marge. Platinum-based schemes have been adopted in the chemoradiation group. The results of chemoradiotherapy, especially in high grade and stage IV cancers, were much superior [13]. 


\section{Patients and Methods}

The purpose of this research is to clarify any additional value of concomitant "chemotherapy" and radiation for resected "high risk" malignant "salivary gland" cancer over postoperative radiation only.

This prospective study design is a clinical randomized phase III study. It will involve 48 patients with surgically excised salivary gland carcinomas involving the major and minor salivary glands of the head and neck.

Patients will be randomized using permuted block method to either arm A or arm B.

1) Postoperative radiation (Arm A):

Radiation: "60 - 70 Gy in 2 Gy daily fractions".

\section{2) Postoperative Concurrent chemoradiotherapy (Arm B):}

Radiation: 60 - 70 Gy in 2 Gy daily fractions with concurrent Cisplatin: 40 $\mathrm{mg} / \mathrm{m}^{2}$ every week during radiation for 6 doses.

\section{Primary end point.}

- Local-regional recurrence free-survival (RFS), which is computed from the date on which adjuvant therapy is completed up to the date of diagnosis of one of the above stated occurrences.

- Distant metastasis free survival (DFS) will be defined from date of end of adjuvant therapy till date of diagnosis of distant metastasis.

\section{Secondary end point.}

- Overall survival (OS) rate calculated from date of diagnosis till date of death or last follows up.

\section{Inclusion Criteria}

Disease Characteristics:

1) "Patients with the major (parotid, sub-mandibular or sublingual) salivary gland carcinomas and the minor head and neck salivary glands with the following histologies":

a) "High-grade adenocarcinoma."

b) "High-grade mucoepidermoid carcinoma."

c) "Salivary duct carcinoma."

d) "High-grade Acinic cell carcinoma."

e) "High-grade ' $>30 \%$ solid component' adenoid cystic carcinoma."

f) "Undifferentiated or poorly differentiated carcinoma", "carcinoma-ex pleomorphic adenoma", "carcinoma NOS".

g) Myoepithelial carcinoma.

2) "Patients with no evidence of hematogenous metastasis, who have undergone curative intent surgical resection and found to have the following risk factors for recurrence":

a) T stage 3 and 4 .

b) N stage 1, 2 and 3 disease.

c) "T stage 1 and $2 \mathrm{~N}$ stage 0 patients with positive or close $(\leq 1 \mathrm{~mm})$ microscopic margins of resection." 
d) "Perineural" invasion.

e) "High grade tumors invasion and positive lymph nodes with extracapsular invasion."

f) Intermediate grade with positive safety or close margin ( $>1 \mathrm{~mm}$ ) margin, perineural invasion and positive lymph nodes with extracapsular invasion.

3) "No prior biologic therapy, chemotherapy or radiotherapy for this malignancy."

4) "No prior breast or thoracic radiotherapy or concurrent regional nodal irradiation."

5) No other concurrent anticancer therapy.

6) Age 18 and over either male or female with performance status WHO 0 - 1.

7) "No other malignancy within the past 5 years except previously treated carcinoma in situ of the cervix or colon, melanoma in situ, or basal cell or squamous cell skin cancer."

8) "No collagen vascular disease (e.g., systemic lupus erythematosus or scleroderma)."

9) "No psychiatric or addictive disorder that would preclude study therapy."

10) "Patients should have a suitable bone marrow function to be defined as a peripheral absolute cell $/ \mathrm{mm}^{3}$ grain cell (AGC), 100,000 cells $/ \mathrm{mm}^{3}$ platelet count, adequate hepatic bilirubin function, $1.5 \mathrm{mg} / \mathrm{mg}$ serum creatinine, SGOT or SGPT $+2 \times$ upper limit, normal serum calcium. SGOT or SGp $=2 \times$ upper limit normal. The clearance of creatine is tested once before randomization."

\section{Exclusion Criteria}

1) "Evidence of metastases (below the clavicle or distant) by clinical or radiographic means."

2) "Prior chemotherapy for any reason or prior radiotherapy to the head and neck."

3) "Initial surgical treatment excluding diagnostic biopsy of the primary site or neck disease."

4) "Patients with simultaneous primaries."

5) "Serum creatinine $>1.5$, creatinine clearance below $50 \mathrm{ml} / 24$ hours, AGC < 2000 , platelets $<100.000$, liver function tests $>2$ times upper limit of normal."

6) The embryotoxic effects of chemotherapy make pregnant women unacceptable.

7) "Patients having a history of non-melanoma or other previous malignancies have been treated for the current malignancy 5 years or fewer."

\section{Results}

Our study randomized "48 patients with resected major and minor salivary gland tumors" with high-risk features to either standard adjuvant radiotherapy versus experimental concomitant chemoradiation. Chemotherapy was in the form of "weekly cisplatin $40 \mathrm{mg} / \mathrm{m}^{2}$ for 6 cycles".

Patient's characteristics: 
Patients were presented to radiotherapy department at National Cancer Institute Cairo University after surgery starting from August 2013 till December 2016. All the patients were sharing high-risk pathological features with no gross disease including stage III and Iva, and also an early stage with poor prognostic factors mentioned in inclusion criteria in patients and methods section. The most common presenting symptom was a mass in the parotid or submandibular gland. Patients with a T4a tumor typically presented with symptoms related to facial nerve dysfunction.

A total of 48 patients were blindly randomized, 23 patients received only adjuvant radiotherapy while 25 patients received concomitant chemoradiotherapy. Patients' characteristics are summarized in Table 1. Mean age in both groups was 48 years, while in radiotherapy arm was 51 years and 46 years in chemoradiotherapy arm. Youngest patient was 21 years old and the oldest was 68 years old.

Female patients represented $56 \%$ (N 27) of patients in the study. Females patients represented most of chemoradiotherapy arm patients (17 out of 25 ) while male patients were more prevalent in radiotherapy arm (13 out of 23).

Parotid gland was the main subsite in the study, around 65\% (31 out of 48 ) of both arms, parotid site was more prevalent in chemoradiotherapy arm (19 patients) than radiotherapy arm (12 patients), while minor salivary glands represented 15\% (12 patients) of all cases (7 in arm 1 and 5 in arm 2), submandibular glands represented 10\% (5 patients) of all cases (4 in arm 1 and 1 in $\operatorname{arm} 2$ ).

Out of the 48 patients in the study 31 patients had parotid gland tumors, 26 patients underwent total parotidectomy, only 5 patients underwent superficial parotidectomy while the rest 17 patients (submandibular and minor salivary gland tumors) underwent wide local excision.

Neck dissection was performed in 29 patients (60\%), only 9 patients of them had lymph node metastases (5 patients in radiotherapy arm and 4 patients in arm 2). A radical neck dissection was modified in ten cases, while the other 19 patients were selectively dissected.

Adenoid cystic carcinoma represented the main pathological type of both arms $56 \%$ (28 patients), $61 \%$ of patients in arm 1 (14 patients) and $56 \%$ of arm 2 (14 patients). Mucoepidermoid carcinoma represented $24 \%$ of pathological types (11 patients), $26 \%$ of patients in arm 1 and $20 \%$ of patients in arm 2 . Adenocarcinoma of salivary gland tumor was only $12 \%$ of patients in the study while only $3(6 \%)$ patients with salivary duct carcinoma and only 1 patient (2\%) patient with myoepithelial carcinoma.

Staging of patients according to the $7^{\text {th }}$ AJCC was used for patients at our study, only 2 patients with T1 (4\%) were included in the study. Patients with T2 represented 30\% (10 patients) and 40\% (10 patients) in arm 1 and arm 2 respectively. Patients with T3 represented $44 \%$ of patients in both groups (10 patients in each arm). Patients with T4a represented $16 \%$ and $17 \%$ in arm 1 and arm 2 respectively. 
Table 1. General patients characteristics.

\begin{tabular}{|c|c|c|c|c|}
\hline & $\begin{array}{c}\text { "Characteristics of } \\
\text { Patients and Tumors" }\end{array}$ & $\begin{array}{l}\text { "Radiation } \\
\text { Group } \\
(\mathrm{n}=23) "\end{array}$ & $\begin{array}{c}\text { "Chemoradiation } \\
\text { Group } \\
(\mathrm{n}=25) "\end{array}$ & p-value \\
\hline \multirow{2}{*}{ Sex } & Female & 10 & 17 & \multirow{2}{*}{0.793} \\
\hline & Male & 13 & 8 & \\
\hline Age & Age, Mean & 51 & 46 & 0.275 \\
\hline \multirow{4}{*}{$\begin{array}{l}\text { Primary } \\
\text { site }\end{array}$} & Parotid gland & 12 & 19 & \multirow{4}{*}{0.394} \\
\hline & Submandibular gland & 4 & 1 & \\
\hline & Sublingual gland & 0 & 0 & \\
\hline & Minor salivary gland & 7 & 5 & \\
\hline \multirow{4}{*}{ T stage } & $\mathrm{T} 1$ & 2 & 1 & \multirow{4}{*}{0.099} \\
\hline & $\mathrm{T} 2$ & 7 & 10 & \\
\hline & T3 & 10 & 10 & \\
\hline & $\mathrm{T} 4$ & 4 & 4 & \\
\hline \multirow{2}{*}{$\mathrm{N}$ stage } & Node negative & 18 & 21 & \multirow{2}{*}{0.332} \\
\hline & Node positive & 5 & 4 & \\
\hline \multirow{3}{*}{$\begin{array}{l}\text { Tumor } \\
\text { stage }\end{array}$} & II & 8 & 8 & \multirow{3}{*}{0.103} \\
\hline & III & 9 & 12 & \\
\hline & IV a & 6 & 5 & \\
\hline \multirow{5}{*}{$\begin{array}{l}\text { Histologic } \\
\text { type }\end{array}$} & Mucoepidermoid carcinoma & 6 & 5 & \multirow{5}{*}{0.22} \\
\hline & Salivary duct carcinoma & 0 & 3 & \\
\hline & myoepithelial carcinoma & 0 & 1 & \\
\hline & Adenoid cystic carcinoma & 14 & 14 & \\
\hline & Adenocarcinoma & 2 & 3 & \\
\hline \multirow{6}{*}{$\begin{array}{l}\text { High-risk } \\
\text { features }\end{array}$} & Positive surgical margin & 12 & 15 & \\
\hline & Close surgical margin & 6 & 7 & 0.32 \\
\hline & Negative margin & & & \\
\hline & Perineural invasion & 14 & 16 & 0.147 \\
\hline & High-grade Histologic characteristics & 12 & 13 & 0.09 \\
\hline & Any of the above & 23 & 25 & \\
\hline
\end{tabular}

Only 9 (5 radiation arm patients and 4 chemoradiotherapy arm patients) out of 29 patients who had surgical neck dissection showed an incidence of pathological metastases of the lymph node.

Incidence of lymph nodes metastases in correlation to pathological types revealed 5 patients with mucoepidermoid carcinoma, 3 patients with adenocarcinoma and 1 patient with adenoid cystic carcinoma.

Stage II patients were $35 \%$ and $32 \%$, stage III was $39 \%$ and $48 \%$ and stage VIa were $26 \%$ and $20 \%$ in radiotherapy arm and chemoradiotherapy arm, respectively.

Overall, 40 of 48 patients (83\%) have close or positive surgical margins and 30 
of 48 patients (62\%) have perineural invasion. Both risk factors are more or less well balanced in both arms with no statistical difference.

The patient features of the chemoradiation group were balanced with those of the radiation-alone group, while the patient proportion was slightly greater in the site, positive surgical margins and perineural chemical invasion. Radiation therapy patients were a little smaller in the group alone and the percentage was greater than in the chemoradiation group with the narrow operational margin.

All patients received radiotherapy are ranging from 60 to 66 Gy using $3 \mathrm{D}$ radiotherapy. Median time interval between surgery and start of treatment was 49 days for both arms. "Median Radiotherapy treatment time was 58 days" for radiotherapy arm versus 65 days for chemoradiotherapy.

In arm of concomitant chemoradiotherapy, all patients received weekly "cisplatin $40 \mathrm{mg} / \mathrm{m}^{2}$ with a median" cumulative dose of $220 \mathrm{mg} / \mathrm{m}^{2}$. All patients received the prescribed 6 cycles except 1 patient who suffered from grade 3 mucositis and severe oral candidiasis and received only 3 cycles.

\section{Treatment outcomes:}

Progression outcome of both groups:

Locoregional recurrence events were observed in 9 (19\%) patients (6 in radiotherapy arm and 3 in chemoradiotherapy arm) after a median time of 36 months. The 2- and 4-year locoregional free survival rates were $90 \%$ and $71 \%$, respectively (Figure 1). Two patients developed regional lymph node recurrence and the rest of recurrences were in the field of high-dose radiotherapy.

The most common form of therapeutic failure was distant metastases and it happened after a median time of 38 months in $16(33 \%)$ patients. The free survival rates for 2 and 4 years were $88 \%$ and 54\%, respectively (Figure 2 and Figure 3). In total, distant metastases of lung, liver, brain and bone were detected in this series.

The trial concluded with the live survival of 34 (70\%) patients (median survivor follow-up time: 46 months; range: 7 - 50 months). In 2 cases there was death from intercurrent disorders ( 1 in radiotherapy arm and 1 in chemoradiotherapy arm). In the overall group, the 2 -year and 4 -year OS rate was $95 \%$ and $65 \%$. For locoregional "patients the median duration of survival was 29 months and for far-off metastases 25 months".

T stage

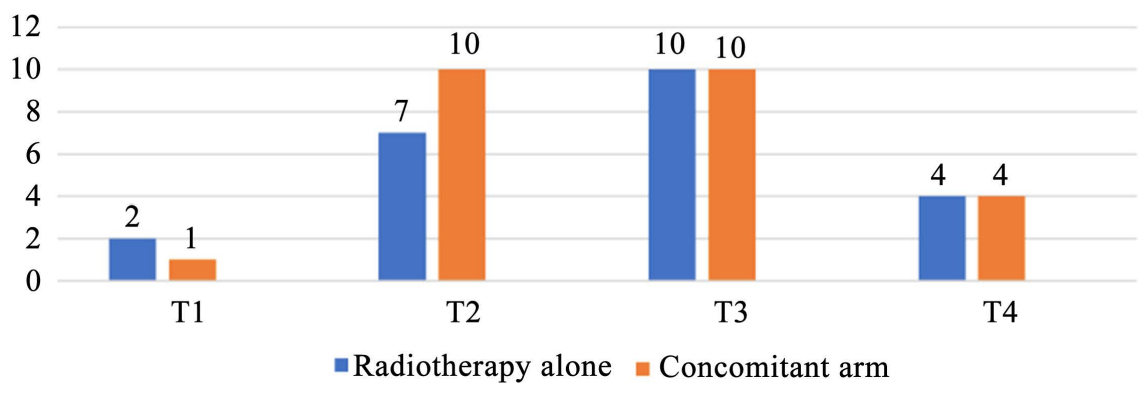

Figure 1. Stage in both arms. 
Local recurrence

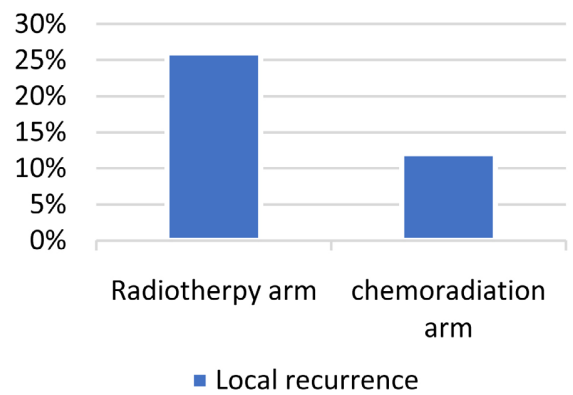

Figure 2. Local recurrence.

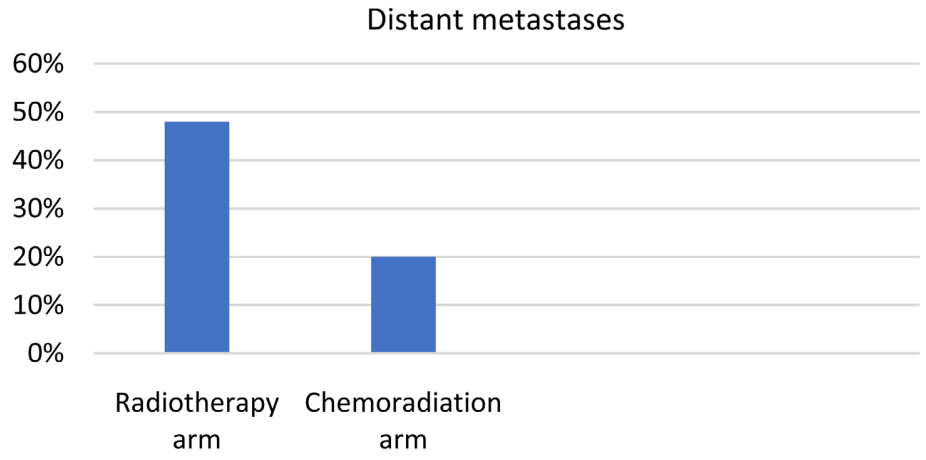

Figure 3. Distant metastases.

Analysis of treatment outcomes of the 48 patients with respect to "site, $\mathrm{T}$ stage, nodal" metastases, "safety margin, perineural invasion and treatment modality" showed presence nodal metastases and perineural invasion have worse outcome, DFS was $76 \%$ for positive lymph node metastases versus $50 \%$ for negative lymph node $(\mathrm{p}=0.006)$. Presence of Perineural invasion is associated with worse outcome with RFS $55 \%$ versus $71 \%(\mathrm{p}=0.011)$, DFS $56 \%$ versus $69 \%(\mathrm{p}=$ $0.007)$ and OS $61 \%$ versus $82 \%(\mathrm{p}=0.036)$ (Table 2$)$.

Comparisons of Adjuvant Postoperative Radiotherapy and Postoperative Chemoradiation arms:

The separation of the survival curves in support of the chemoradiation group was assessed based on treatment and multivariate analysis. In the chemoradiation group, median locoregional Recurrence Free Survival was 49 months compared to 37.9 months for radiation alone. The estimated 2 and 4-year Locoregional progression-free survival rate in the chemoradiation group ( $\mathrm{p}=0.007$ by $\log$ rank) was $95 \%$ and $73 \%$, respectively, compared to $77.4 \%$ and $43.6 \%$ in the radiation-alone group (Figure 4).

The 2 - and 4 years distant free metastases in chemoradiation arm were $100 \%$ and $59 \%$ versus $68 \%$ and $39 \%$ in radiation arm, respectively $(\mathrm{p}=0.08)$ (Figure $5)$.

In the group of chemoradiation, the median overall survival was 48 months compared with 40 months in the group of radiation-alone. In the chemoradiation group, overall survival for the predicted 2- and 4-year periods was $93 \%$ and 


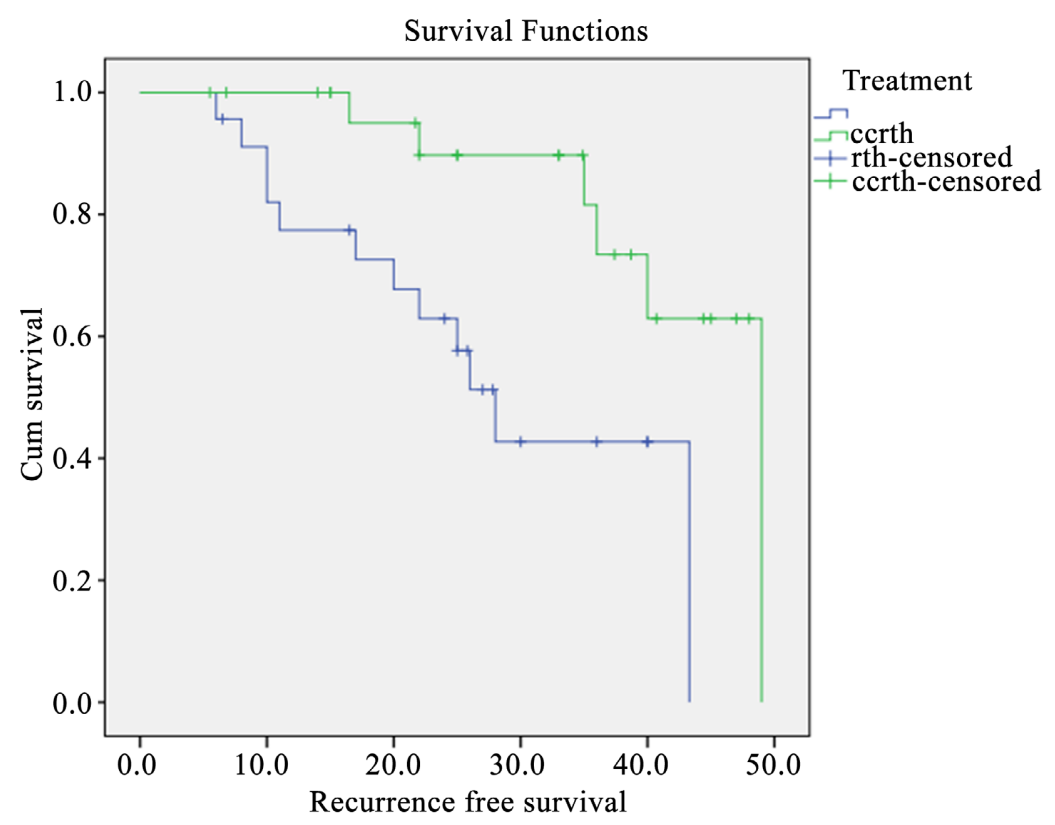

Figure 4. Locoregional recurrence free survival in both arms $(\mathrm{p}=0.007)$.

Table 2. Prognostic factors of cohort study.

\begin{tabular}{|c|c|c|c|c|c|c|c|}
\hline \multicolumn{2}{|c|}{ variable } & \multicolumn{2}{|l|}{ RFS } & \multicolumn{2}{|l|}{ DFS } & \multicolumn{2}{|l|}{ OS } \\
\hline \multirow{5}{*}{ T stage } & $\mathrm{T} 1$ & $90 \%$ & \multirow{5}{*}{0.437} & $84 \%$ & & $80 \%$ & \multirow{5}{*}{0.437} \\
\hline & $\mathrm{T} 2$ & $88 \%$ & & $67 \%$ & & $70 \%$ & \\
\hline & & & & & 0.756 & & \\
\hline & T3 & $82 \%$ & & $61 \%$ & & $66 \%$ & \\
\hline & $\mathrm{T} 4 \mathrm{a}$ & $71 \%$ & & $58 \%$ & & $50 \%$ & \\
\hline \multirow{2}{*}{$\begin{array}{l}\text { Nodal } \\
\text { status }\end{array}$} & Positive & $85 \%$ & \multirow[b]{2}{*}{0.536} & $50 \%$ & \multirow[b]{2}{*}{0.006} & $60 \%$ & \multirow[b]{2}{*}{0.055} \\
\hline & negative & 78.5 & & $76 \%$ & & $70 \%$ & \\
\hline \multirow{3}{*}{ Stage } & Stage II & $77 \%$ & \multirow{3}{*}{0.734} & $75 \%$ & & $79 \%$ & \multirow{3}{*}{0.136} \\
\hline & Stage III & $71 \%$ & & $71 \%$ & 0.45 & $72 \%$ & \\
\hline & Stage IVa & $66 \%$ & & $66 \%$ & & $59 \%$ & \\
\hline \multirow{3}{*}{$\begin{array}{l}\text { Safety } \\
\text { margins }\end{array}$} & positive & $72 \%$ & \multirow{3}{*}{0.828} & $51 \%$ & & $54 \%$ & \multirow{3}{*}{0.521} \\
\hline & Close & $79 \%$ & & $57 \%$ & 0.335 & $66 \%$ & \\
\hline & negative & $81 \%$ & & $60 \%$ & & $69 \%$ & \\
\hline \multirow{2}{*}{$\begin{array}{l}\text { Perineural } \\
\text { invasion }\end{array}$} & Positive & $55 \%$ & \multirow[b]{2}{*}{0.011} & $56 \%$ & & $61 \%$ & \multirow[b]{2}{*}{0.036} \\
\hline & negative & $71 \%$ & & $69 \%$ & 0.007 & $82 \%$ & \\
\hline \multirow{2}{*}{$\begin{array}{l}\text { Treatment } \\
\text { modality }\end{array}$} & RTH & $43.6 \%$ & \multirow{2}{*}{0.007} & $62.5 \%$ & & $48 \%$ & \multirow{2}{*}{0.009} \\
\hline & CCRTH & $73 \%$ & & $83 \%$ & 0.003 & $78 \%$ & \\
\hline
\end{tabular}

(RFS: locoregional recurrence free survival. DFS: distant metastases free survival. OS: overall survival).

$78 \%$, but in the individual group, respectively, $95 \%$ and $48 \%$. This was significant statistically “ $\mathrm{p}=0.009$ by log-rank test” (Figure 6). 


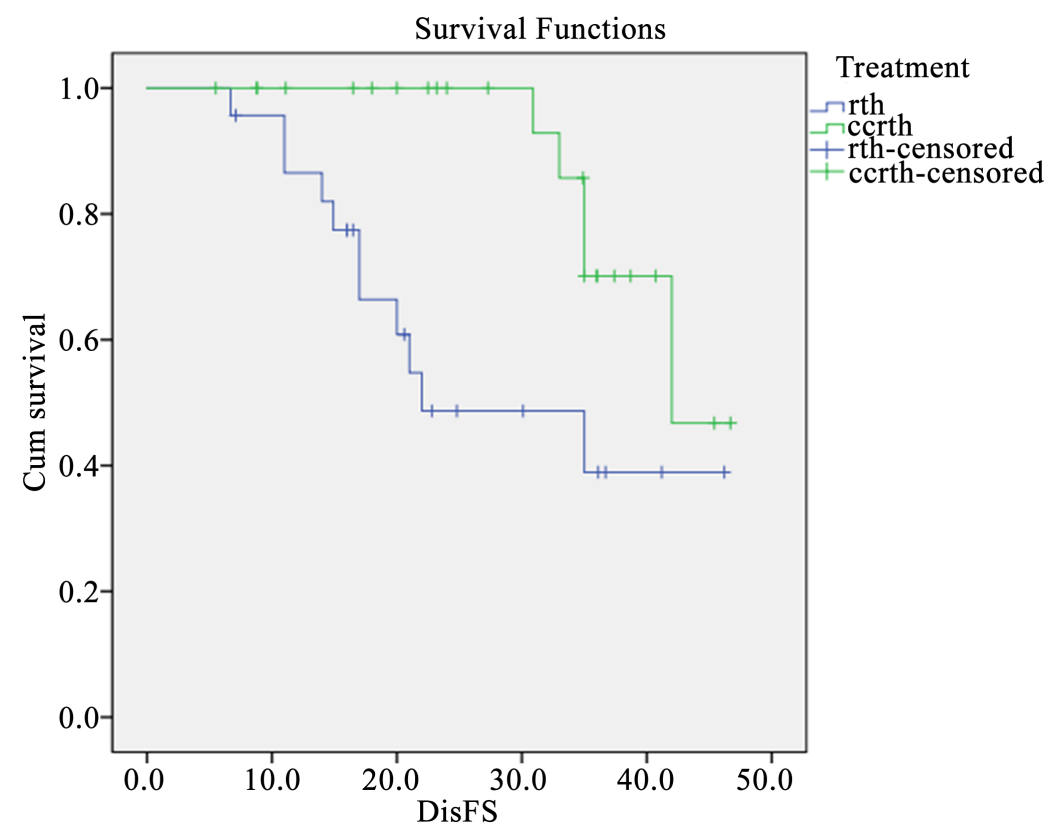

Figure 5. Distant metastases free survival in both arms $(\mathrm{p}=0.08)$.

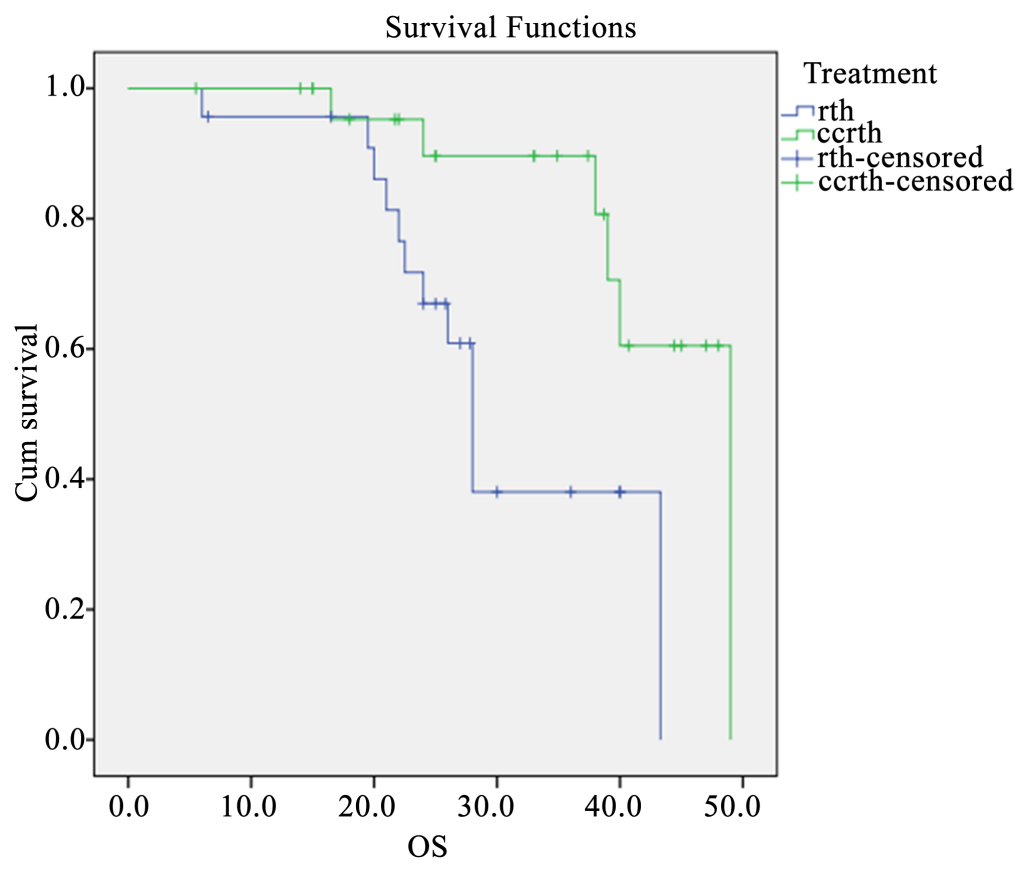

Figure 6. 4 years overall survival $(\mathrm{p}=0.009)$.

We performed subgroup analysis with the goal of identifying specific subgroups of salivary gland tumors patients who can benefit most from postoperative chemoradiation. Analysis of prognostic factors in correlation to treatment modalities revealed stage III and IVa have median 4 years locoregional free survival $71 \%$ arm versus $66 \%(\mathrm{p}=0.15)$, DFS was $58 \%$ versus $44 \%(\mathrm{p}=0.04)$ and overall survival was $67 \%$ versus $56 \%(\mathrm{p}=0.004)$ in chemoradiotherapy arm versus radiotherapy arm respectively. 
Positive margin was associated with median locoregional recurrence free survival $80 \%$ versus72\% ( $\mathrm{p}=0.79)$, DFS was $75 \%$ versus $63 \%(0.034)$ and median overall survival was $74 \%$ versus $63 \%(\mathrm{p}=0.011)$ in chemoradiation arm versus radiotherapy arm alone respectively.

Perineural invasion was associated with median locoregional recurrence free survival was $85 \%$ versus $84 \%(\mathrm{p}=0.108)$, median DFS was $83 \%$ versus $58 \%(0.02)$ and median overall survival was $61 \%$ versus $33 \%(\mathrm{p}=0.03)$ in chemoradiation arm versus radiotherapy arm alone respectively (Table 3 and Figures 7-14).

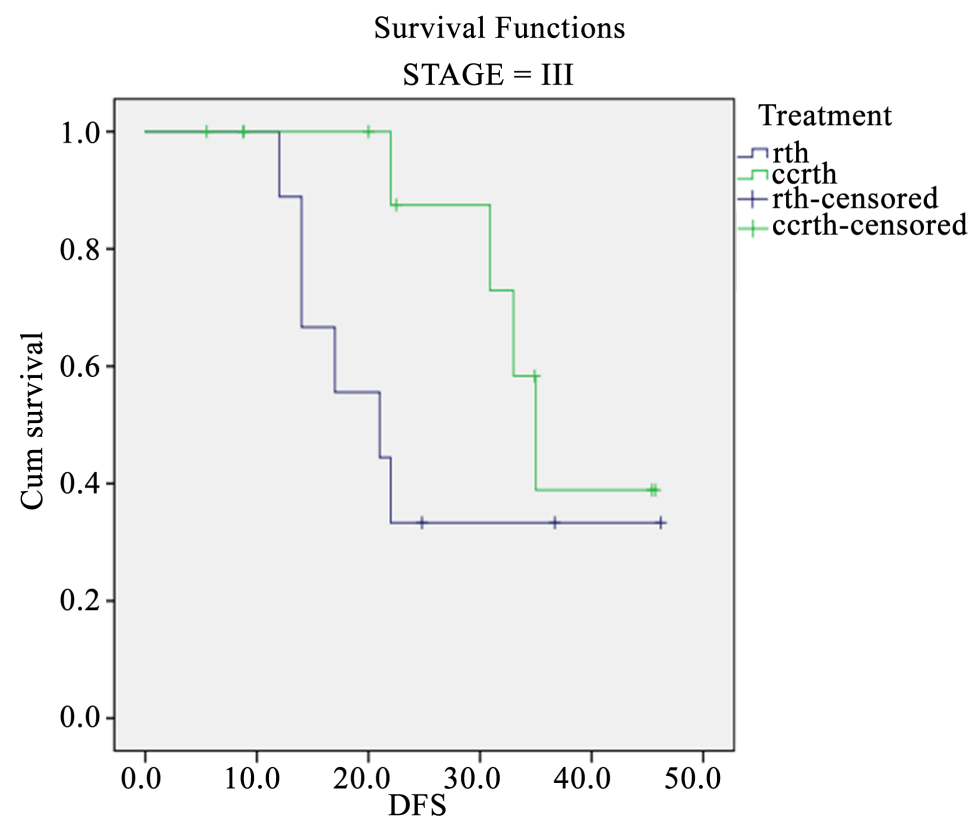

Figure 7. Stage III DFS $(\mathrm{p}=0.04)$.

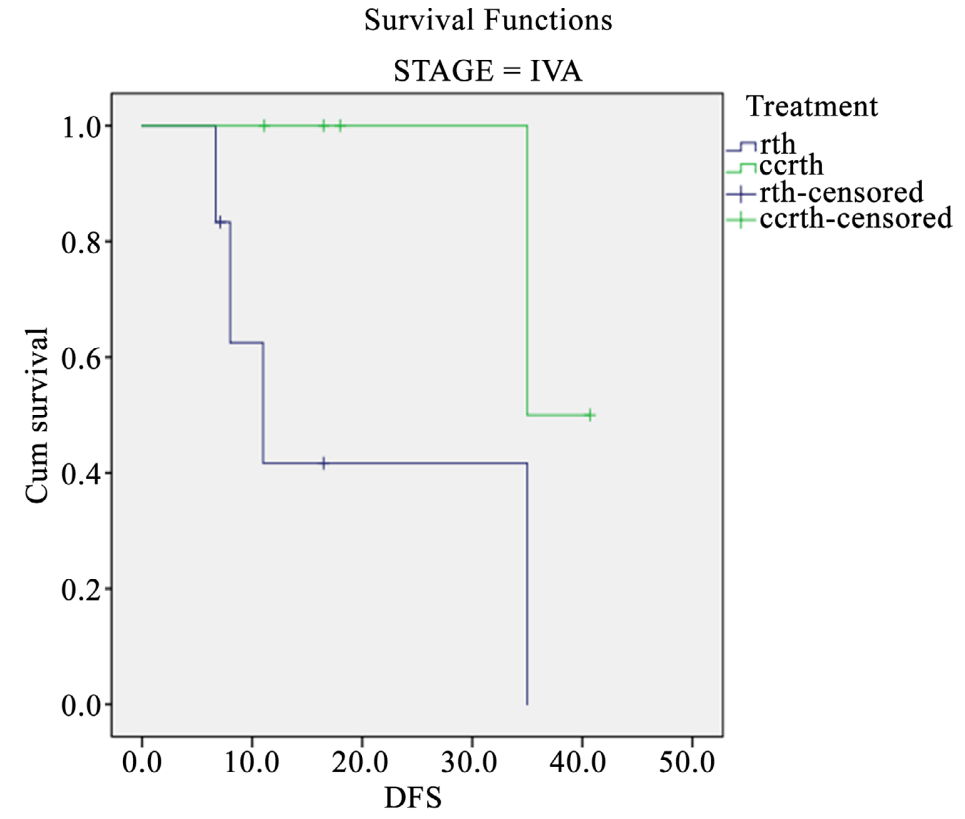

Figure 8. Stage IVa DFS $(\mathrm{p}=0.04)$. 


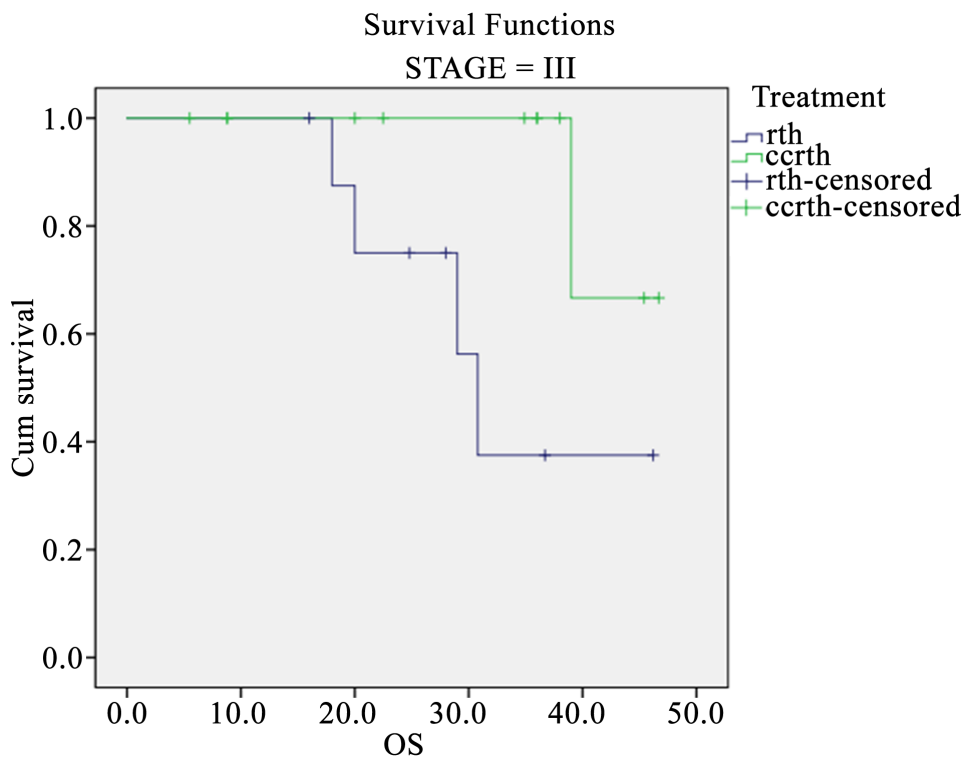

Figure 9. Stage III overall survival $(\mathrm{p}=0.004)$.

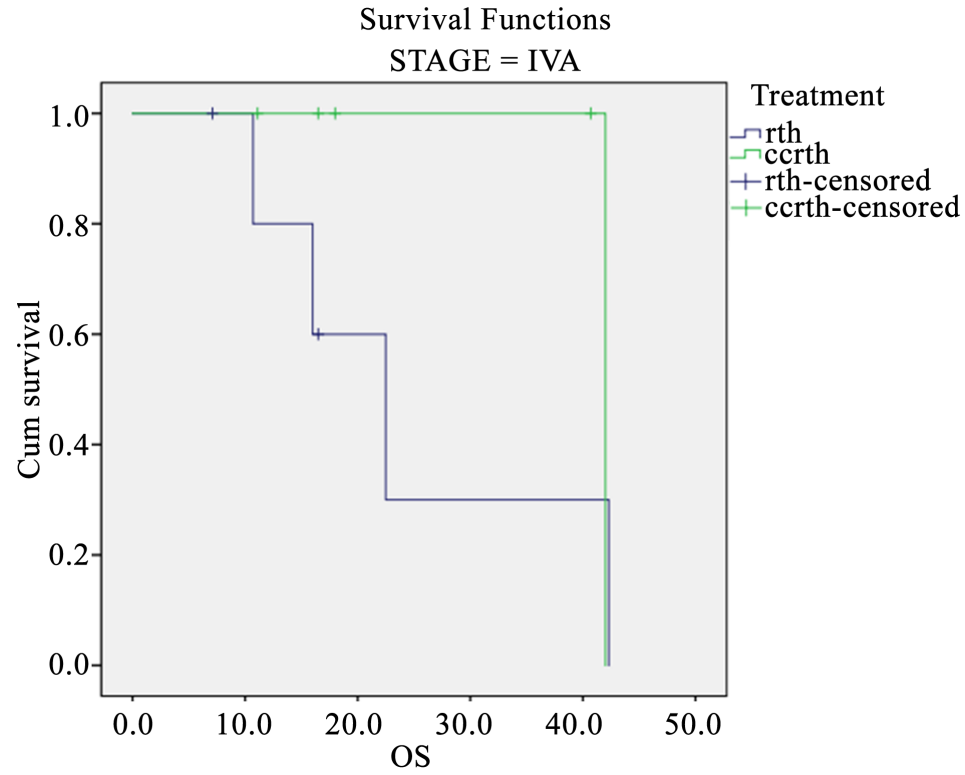

Figure 10. Stage IVa Overall survival $(\mathrm{p}=0.004)$.

Table 3. Prognostic outcomes according to treatment modality.

\begin{tabular}{cccccccc}
\hline variable & Treatment modality & RFS & p & DFS & p & OS & p \\
\hline $\begin{array}{c}\text { Stage } \\
\text { III-IVa }\end{array}$ & radiotherapy & $66 \%$ & 0.15 & $44 \%$ & 0.04 & $56 \%$ & \multirow{2}{*}{ Conc-chemoradiotherapy } \\
\hline $\begin{array}{c}\text { Positive } \\
\text { margin }\end{array}$ & radiotherapy & $72 \%$ & & $58 \%$ & & $67 \%$ & 0.004 \\
\hline $\begin{array}{c}\text { Perineural } \\
\text { invasion }\end{array}$ & Conc-chemoradiotherapy & $80 \%$ & & $75 \%$ & & $74 \%$ & 0.011 \\
\hline
\end{tabular}

(RFS: locoregional recurrence free survival. DFS: distant metastases free survival. OS: overall survival). 


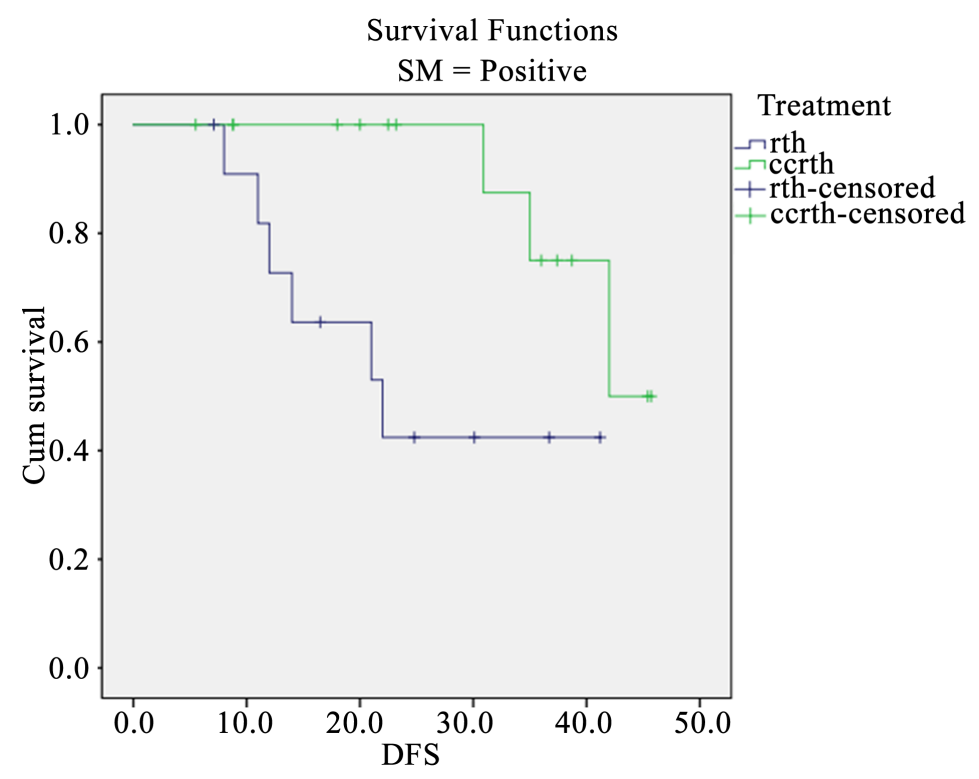

Figure 11. Safety margin DFS $(\mathrm{p}=0.034)$.

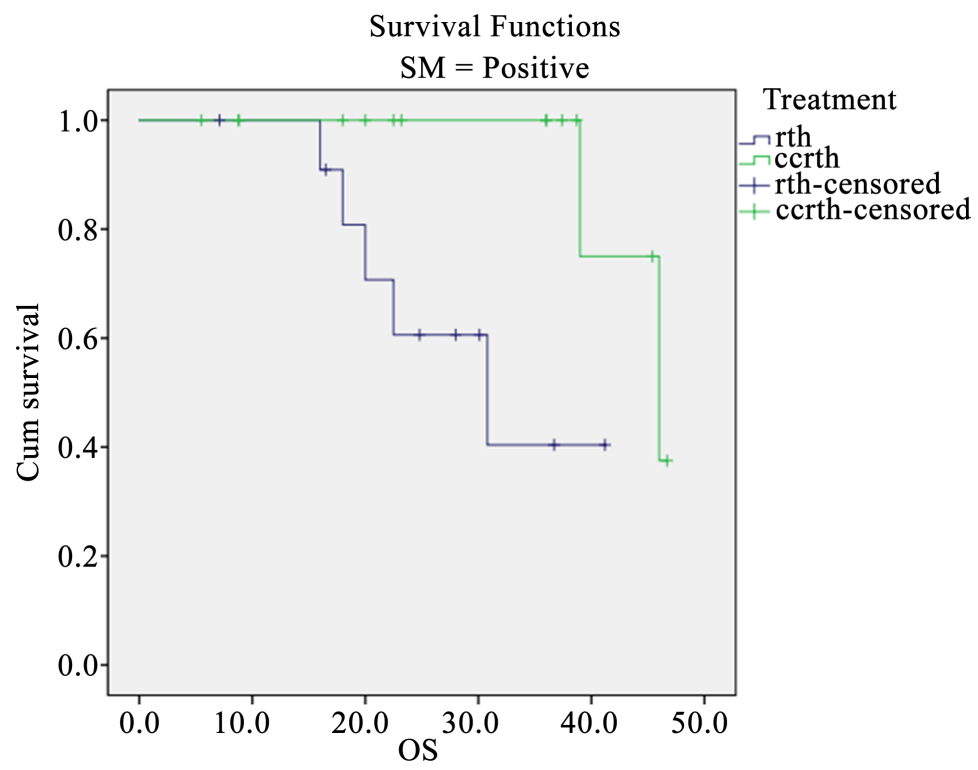

Figure 12. Safety margin overall survival $(\mathrm{p}=0.011)$.

\section{Treatment related complications:}

Chemoradiation was well tolerated at the same time. Radiation therapy due to toxic effects was not interrupted. In the two groups, radiation dermatitis and mucositis were the most adverse effects. In the chemoradiation group Grade 3 or higher, mostly hematologic, toxic effects were more frequent than in the radiation-alone. Grade 3 or higher (67\%) were present in the concomitant group of chemo radiated agents, but they were observed in the radiation-alone group (17\%). Hematological toxic effects followed by mucositis and dermatitis were the most frequent toxic effects. In both groups, long-term adverse events, mainly dry mouth, were mild (Table 4). 


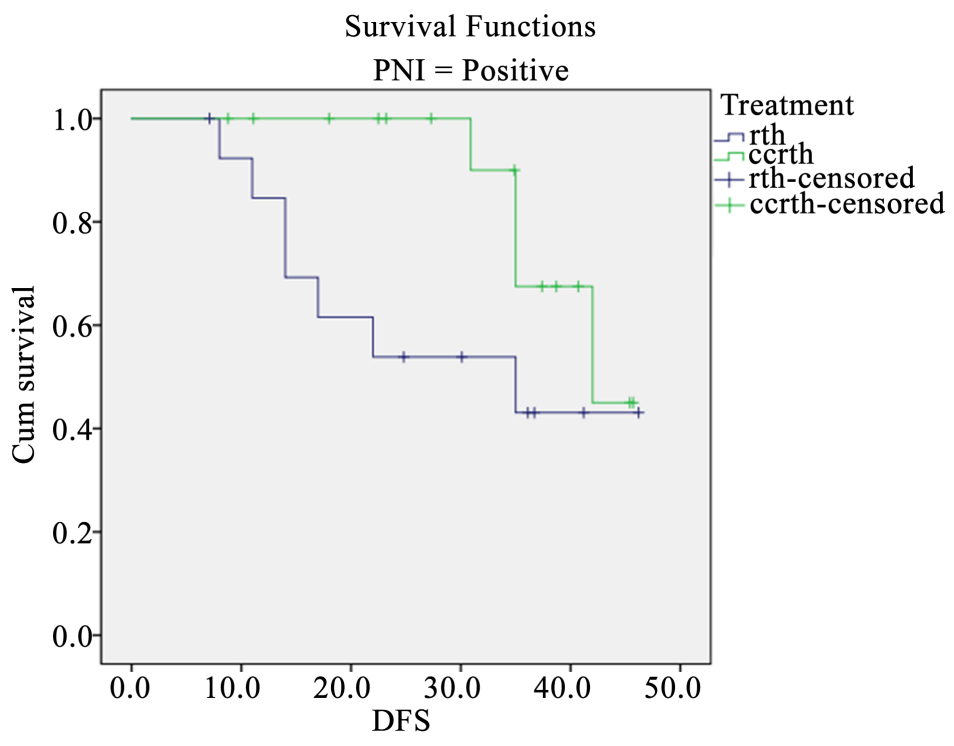

Figure 13. PNI disease free survival $(\mathrm{p}=0.02)$.

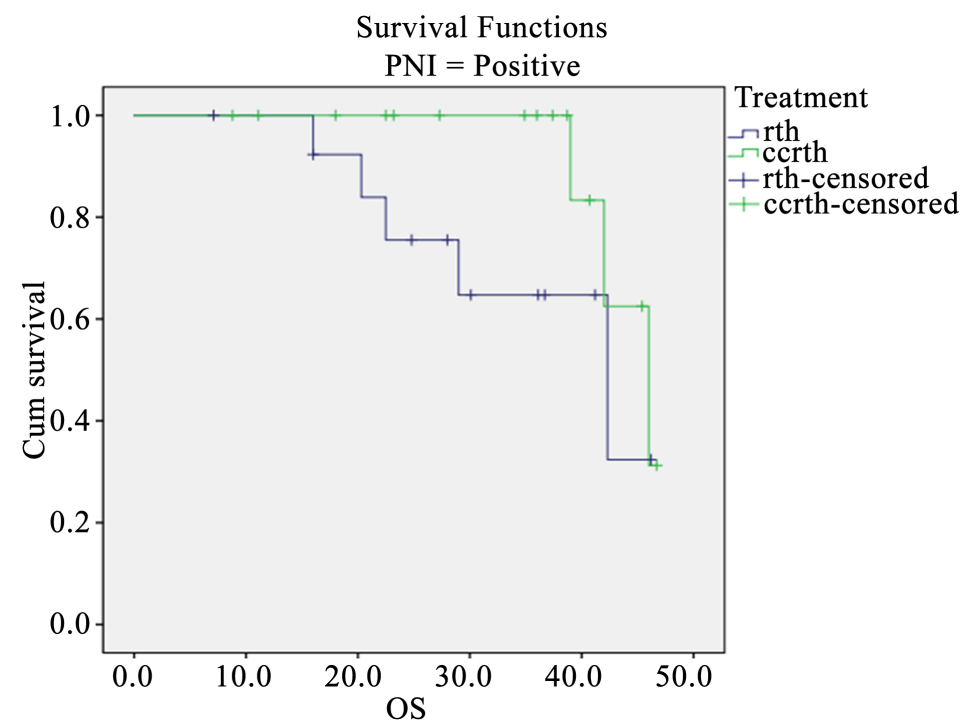

Figure 14. PNI overall survival $(\mathrm{p}=0.03)$.

Table 4. Grade 3 and 4 toxicities in both arms.

\begin{tabular}{cccc}
\hline & & Radiotherapy arm & Chemoradiotherapy \\
\hline \multirow{2}{*}{ Dermatitis } & grade 3 & $17.5 \%$ & $16 \%$ \\
& grade 4 & nil & $16 \%$ \\
\hline \multirow{2}{*}{ Mucositis } & grade 3 & $17 \%$ & $56 \%$ \\
& grade 4 & nil & $8 \%$ \\
\hline \multirow{2}{*}{ Vomiting } & grade 3 & nil & $28 \%$ \\
& grade 4 & nil & nil \\
\hline \multirow{2}{*}{ Neutropenia } & grade 3 & nil & $20 \%$ \\
& grade 4 & nil & nil \\
\hline \multirow{2}{*}{ Skin fibrosis } & grade 3 & $4 \%$ & $28 \%$ \\
& grade 4 & nil & nil \\
\hline
\end{tabular}




\section{1) Acute dermatitis toxicity:}

Grade 1 and 2 dermatitis was $82.5 \%$ in radiotherapy arm 1 while it represented $68 \%$ in concomitant chemo radiotherapy arm. Grade 3 and 4 were $17.5 \%$ in arm 1 while it represented $17.5 \%$ and $32 \%$ in radiotherapy arm and chemoradiotherapy arm, respectively.

\section{2) Mucositis toxicity:}

Rate of grade 1 and 2 mucositis in radiotherapy arms was $83 \%$ while in concomitant chemoradiotherapy arm was $36 \%$. Grade 3 and 4 mucositis was $17 \%$ in radiotherapy arm and $64 \%$ in concomitant chemoradiotherapy arm.

\section{3) Vomiting toxicity:}

Vomiting is common toxicity of cisplatin chemotherapy. Rate of vomiting toxicity in radiotherapy arm was almost nil only 1 patient suffered from grade 1 vomiting toxicity while in concomitant arm $28 \%$ suffered from grade 3 and $72 \%$ suffered from grade 2 vomiting toxicity.

\section{4) Neutropenia:}

$0 \%, 20 \%, 28 \%$ of patients in concomitant arm suffered from grade 4 , grade 3 and grade 2 toxicities respectively while only 3 patients (13\%) in radiotherapy arm suffered from grade 1 neutropenia toxicity.

\section{5) Skin fibrosis:}

Skin fibrosis grade 0, 1, 2 was around $4 \%, 66 \%$ and $26 \%$ in radiotherapy arm and $0 \%, 40 \%$ and $28 \%$ in concomitant arm respectively.

\section{6) Renal dysfunction:}

For patients in chemoradiation arm, weekly renal function assessment was done with no detectable impairment.

\section{Discussion}

This prospective study of using combined chemotherapy with standard adjuvant radiotherapy for resected major and minor salivary gland tumors with high risk pathological features to improve treatment outcome for these rare head and neck tumors and asses efficiency of addition weekly cisplatin was the main aim. The theoretical strategy was extrapolated from the famous RTOG and EORTC trials of combined cisplatin with postoperative radiotherapy for head and neck squamous cell carcinoma, but the rarity and pathological heterogenicity of salivary gland tumors was the main obstacle of this study compared to head and neck squamous cell tumors.

The study randomized 48 patients into arm 1 who received adjuvant radiotherapy alone while arm 2 received in addition to standard adjuvant radiotherapy weekly cisplatin for 6 cycles. Mean age in the study was 48 years, while female patients represented $56 \%$ of patients in the study, the WHO reported the sixth decade is the mean age of salivary glands incidence with equality of sex distribution [3].

Parotid gland was the main subsite in the study, around $65 \%$ of patients, while minor salivary glands represented $15 \%$ of all cases and submandibular glands 
represented $10 \%$ of all cases. Data of the Swedish Cancer Registry showed that between 1960 and 1989, there are 2557 cases of large salivary gland diseases. Adenoid cyst carcinoma (20\%), MS carcinoma (19\%), malignant, mint tumorous (14\%), Adenocarcinoma (13\%), AC (12\%), and SCC (6\%) were the most prevalent types of histology and parotids were the primary adenoid cystic adenocarcinoma (57.5\%) and are the most common types (10\%) [4].

Armstrong et al. reported the rate of cervical lymph node metastasis in review of 474 patients is only " $14 \%$ of patients with salivary gland" malignancies. Most pathological types associated with neck metastases were Anaplastic carcinoma (86\%), Adenocarcinoma (22\%), Mucoepidermoid (14\%), Acinic (2\%) and Adenoid cystic (2\%). In our study incidence of pathological lymph node metastases was proven in only $18.75 \%$ of patients and in correlation to pathological types adenocarcinoma had the highest incidence (60\%), while $35 \%$ of mucoepidermoid carcinoma and $4 \%$ of adenoid cystic carcinoma have pathological lymph nodes metastases [7].

The 5-year relative survival rate for salivary gland tumors was 93 percent for stage I and II, 67 percent for stage III, 44 percent for stage IV, and 72 percent for all SEER stages combined. Our trial ended with $70 \%$ of patients alive. Stage II had a 4 -year overall survival of $65 \%$, whereas stage III had a $67 \% 4$-year overall survival and stage IVa had a 59\% 4-year overall survival [14].

In our study, $19 \%$ of people had recurrences. The 4-year Free Survival Rate was $71 \%$. Distant metastases were the most common type of therapeutic failure (33\%). The 2-year and 4-year FS metastatic rates were $88 \%$ and $54 \%$. Fu et al., University of California, investigated 100 "major and minor salivary" tumors' treatment outcomes by stage and approach. Post-operative radiation has improved local control rates of adenoid cystic carcinoma and advanced local disease in microscopic sickness. Local recurrence occurred in 14\% of postoperative radiation patients and 54\% of non-microscopic or surgical range patients. Regional lymph node failure was rare but happened at the initial or distant metastatic tumor location [15].

In the treatment of large salivary cancers, the utilization of postoperative radiology therapy plays a strong and crucial role. In selected circumstances, their hiring significantly improves local control. However, randomized studies in the literature of the world are not available. The use of postoperative radiation has few high clinical data to support it. The findings are confined to retrospective reports describing better rates of local control in comparison with surgery alone. In patients who suffer from this condition, register information and a single institution series consistently reveal an improved survival over time. This is partly because of enhanced surgical technique, but mostly because post-operative radiation has been widely used [7].

Despite its largely indolent course, local recurrence and remote metastases remain substantial clinical problems in salivary tumors, especially if vigorous treatment techniques were used, patients with unfavorable prognostic characteristics. Postoperative concurrent radiation therapy has proved to provide surviv- 
al benefits and is integrated into the current treatment standards in patients with locally advanced head/neck squamous cell carcinomas. However, the topic whether the inclusion of competitor chemotherapy can improve result in patients with post-operative radiation with salivary gland malignancies remains open. Accordingly, there are scant and conflicting data available on the clinical value of postoperative chemoradiation for salivary gland cancer patients in future studies.

Data on concomitant adjuvant chemoradiotherapy following resection are restricted. In 2016 "Amini et al. reviewed data for patients with resected Major Salivary Gland Carcinoma" in order to examine the overall survival (OS) "outcomes from a National Cancer Data Base” associating chemoadia with radiation alone. Analysis included 2210 patients, radiotherapy was received in 1842, and chemical radiation treatment was received in 368. Unadjusted 2-year OS was much poorer than 5 -year OS (38.5 per cent vs. 54.2 per cent) with adjuvant chemoradiotherapy compared radiation alone "71.3 per cent vs. 80.2 per cent". In comparison with radiation alone, survival was lower with adjuvant multivariate analysis chemoradiation $(\mathrm{p}=0.02)$. Age, coorbidity range, main location, histological type, grade, stage $\mathrm{T}$, stage $\mathrm{N}$, margin and chemical (single agent versus multi-agent) analysis showed a corresponding or shorter OS with added chemotherapy. Chemotherapy was shown as a result of radiation treatment [16].

However, Taventynon (matched instances) and Schoenfeld etcetera published results show adverse selection criteria in chemotherapy patients [12] [13].

The bulk of published research to evaluate the advantage of chemotherapy being added to radiation treatment is retrospective. There are just a few prospective phase II studies which show the need for greater data for competitor chemo in salivary gland cancers. An important restriction in the design of randomized clinical studies is the extremely rare and heterogeneous salivary cancers. The death range therefore varies between $6 \%$ to $97 \%$ among histologies, suggesting various behaviors and probable distinct selection processes. Such factors may require concomitant chemotherapy in addition to high-dose radiation therapy, including the TNM phase, tumors, degree, perineural invasion, surgical or unresectable diseases and certain locations (i.e. submandibular gland, deeper lobe of the Parotid Gland being worse). Although studies have not shown an advantage in chemotherapy in general, selection distortions strongly support chemotherapy (worst prognosis cases are selected to receive chemotherapy).

Re-examination 91 individuals receiving surgical treatment with adenoid cystic carcinoma are followed by radiation or concurrent chemoradiotherapy. The most routinely employed chemotherapy schedules were cisplatin-based concurrent regimens. Patients getting chemoradiotherapy revealed that they were in the whole research cohort at 5 to 8 years of age (97\% versus $84 \%$ and $79 \%$ ), respectively, at a trend towards greater LRC rates than those received with radiotherapy alone; $p=0.066$ ). The most common kind of therapy failure was remote metastases, which occurred in 31 patients (34 percent) (PORT, $\mathrm{n}=17$; POCRT, $\mathrm{n}=$ 14). Chemoradiotherapy patients had 97 and $97 \%$ LRC rates, respectively, for 5- 
and 8 -year years, as compared with $79 \%$ and $67 \%$, for radiation-alone T-treated patients $(p=-017)$. In terms of remote metastases free survival and overall survival, the two groups did not differ significantly (OS). Subgroup tests showed a substantially 5- and 8-year-old LRC patient with Phase III - IV ( $p=0.040$ and $0.017)$, positive surgical margins $(p=0.011$ and 0.050$)$ or perineural invasions ( $p$ $=0.013$ and 035), respectively, in chemoradiation treatment [17].

In the chemoradiation group compared to radiation alone $(\mathrm{p}=0.07)$, the estimated 2- and 4-year locoregional progression-free survival rates were $77.4 \%$, $95 \%$ compared with $73.6 \%$ respectively $(\mathrm{p}=0.007)$. It is projected that DFS rates for 2 and 4 years in the chemoradiation group were $90 \%$ vs. $77 \%$ and $83 \%$ vs. $62.5 \%$ in the radiation-alone group $(p=0.03)$. Free metastases in the chimera radiation arm were $100 \%$ vd $68 \%$ and $59 \%$ vs $39 \%$ correspondingly $(\mathrm{p}=0.08)$ for 2 - and 4-year-old. In the chemoradiation group correspondingly, the projected overall survival over four years was $78 \%$ compared to $48 \%$ for the radiation-alone group $(\mathrm{p}=0.009)$.

Patients who benefit most from postoperative chemical radiation can use sub-group studies to identify specific subgroups of salivary gland malignancy. Analysis of prognostic variables for treatment modes revealed in stage III and IVa were median 4 years free of locoregional survival of $71 \%$ vs. $66 \%(\mathrm{p}=0.15)$, DFS of $58 \%$ vs. $44 \%$ “ ( $p=0.04)$, with overall survival of $67 \%$ vs. $56 \%(p=0.004)$, respectively", for chemical-radiation-therapy arm vs. radiotherapy arm.

The positive range is 80 percent from 72 percent $(p=0.79)$ for Locoregional recurrence free survival, 75 percent against 63 percent (0.034) for DFS, and 74 percent for Medium overall survival ( $p=0.011$ ), compared to 63\% ( $p=0.011$ ). The median recurrence free survival of perineural invasions was $85 \%$, compared to $84 \%$ ( $p=0.108)$, the median DFS was $83 \%$ compared to $58 \%(p=0.02)$ and total median survival was $61 \%$, compared with $0.03 \%$ for chemoradiation against radiotherapy arm alone.

The results show the possibility to create considerable radiosensitization of salivary gland cancers with concurrent treatment. Only a small number of published research examined the viability of chemoradiation "therapy in patients with salivary gland cancers", with the majority focused on the potential benefits of definitive chemotherapy.

Distant metastases were the major pattern of treatment failure and the most common cause of disease-specific mortality in our investigation, according to the data reported. While our findings show that adding concomitant chemotherapy to radiation treatment greatly decreased local regional relapses, hematogenic expansion among these individuals decreased. The probability of a remote failure remains substantial even with managed locoregional diseases in patients with several adverse predictive variables. Moreover the median survival for patients with recurrence is believed to be 2 - 3 years due to the slowly progressing course of salivary gland cancers. The median time of survival after a local-regional recurrence diagnosis was 29 months in our study sample (range: 7 50 months). 
Despite all efforts to carry out a very detailed assessment of our data and several statistical exams, certain limitations inherent in our studies are nonetheless inescapable. The long registration period includes. Our results may have been biased by the comparatively small number of occurrences in this observational cohort and a number of unmeasured confounders (including subjective treatment decisions and time-limited surgical expertise). Furthermore, it cannot be excluded that individuals with concurrent chemotherapy, in addition to postoperative radiotherapy, have underestimated side-effects connected to treatments.

Competitive chemoradiation has been well tolerated in our investigation. Radiation therapy due to harmful effects was not interrupted. In the two groups, radiation dermatitis and mucositis were the most unfavorable consequences. In the chemoradiation group Grade 3 or above, predominantly hematologic, toxic effects were more frequent than in the radiation-alone. Grade 3 or above (67\%) were found in the concomitant group, although they were observed in the radiation-alone group (17\%). Hematological toxic effects followed by mucositis and dermatitis were the most frequent toxic consequences. In both groups, longterm adverse effects, mainly dry mouth, were minor.

\section{Conclusions}

The conventional therapy of malignant salivary gland patients without proof of remote blood cell metastases remains adjuvant radiation surgery. This method facilitated the care of local tumors against the procedure alone. These significant gains in regional management had a late effect on the patient's survival. Noticeably poor results with advanced salivary cancer are attributable to distant metastases, despite the high rates of local disease care.

In the event of phase III - IV disease, positive surgery or perineal invasion, improved local control, free disease survival, free survival, and overall survival rates in the presence of salivary glandular tumors, the results of our study show that the addition of concomitant chemotherapy as a radio-sensitizer by weekly cisplatin.

\section{Conflicts of Interest}

The authors declare no conflicts of interest regarding the publication of this paper.

\section{References}

[1] Boukheris, H., Curtis, R.E., Land, C.E. and Dores, G.M. (2009) Incidence of Carcinoma of the Major Salivary Glands According to the WHO Classification, 1992 to 2006: A Population-Based Study in the United States. Cancer Epidemiol Biomarkers \& Prevention, 18, 2899-2906. https://doi.org/10.1158/1055-9965.EPI-09-0638

[2] Mifsud, M.J., Burton, J.N., Trotti, A.M. and Padhya, T.A. (2016) Multidisciplinary Management of Salivary Gland Cancers. Cancer Control, 23, 242-248.

https://doi.org/10.1177/107327481602300307 
[3] Ellis, G.L. and Auclair, P.L. (1996) Tumors of the Salivary Glands, Atlas of Tumor Pathology: Third Series. American Registry of Pathology, Washington, DC.

[4] Spiro, R.H., Armstrong, J., Harrison, L., Geller, N.L., Lin, S. and Strong, E.W. (1989) Carcinoma of Major Salivary Glands: Recent Trends. Archives of Otolaryngology-Head and Neck Surgery, 115, 316-321. https://doi.org/10.1001/archotol.1989.01860270058015

[5] Terhaard, C.H., Lubsen, H., Van der Tweel, I., Hilgers, F.J., Eijkenboom, W.M., Marres, H.A., Tjho-Heslinga, R.E., de Jong, J.M. and Roodenburg, J.L. (2004) Salivary Gland Carcinoma: Independent Prognostic Factors for Locoregional Control, Distant Metastases, and Overall Survival: Results of the Dutch Head and Neck Oncology Cooperative Group. Head \& Neck, 26, 681-693.

https://doi.org/10.1002/hed.10400

[6] Spiro, R.H. (1998, May) Management of Malignant Tumors of the Salivary Glands. Oncology (Williston Park), 12, 671-680.

[7] Armstrong, J.G., Harrison, L.B., Spiro, R.H., Fass, D.E., Strong, E.W. and Fuks, Z.Y. (1990) Malignant Tumors of Major Salivary Gland Origin. A Matched-Pair Analysis of the Role of Combined Surgery and Postoperative Radiotherapy. Archives of Otolaryngology_Head and Neck Surgery, 116, 290-293.

https://doi.org/10.1001/archotol.1990.01870030054008

[8] Ahmed, M.M.E. (2021) Polymyxins: "Last Resort" for MDR and/or XDR GramNegative Infections. Journal of Scientific Research in Medical and Biological Sciences, 2, 123-141. https://doi.org/10.47631/jsrmbs.v2i3.242

[9] Lagha, A., Chraiet, N., Ayadi, M., Krimi, S., Allani, B., Rifi, H., Raies, H. and Mezlini, A. (2012) Systemic Therapy in the Management of Metastatic or Advanced Salivary Gland Cancers. Oral Oncology, 48, 948-957. https://doi.org/10.1016/j.oraloncology.2012.05.004

[10] Jemiluyi, O.O. and Bank-Ola, R.F. (2021) The Burden of Infectious Diseases: A Trend Appraisal in Sub-Saharan Africa Regional Trade Blocs. Journal of Scientific Research in Medical and Biological Sciences, 2, 104-122.

[11] Cooper, J.S., Pajak, T.F., Forastiere, A.A., Jacobs, J., Campbell, B.H., Saxman, S.B., Kish, J.A., Kim, H.E., Cmelak, A.J., Rotman, M., Machtay, M., Ensley, J.F., Chao, K.S., Schultz, C.J., Lee, N. and Fu, K.K. (2004, May 6) Postoperative Concurrent Radiotherapy and Chemotherapy for High-Risk Squamous-Cell Carcinoma of the Head and Neck. The New England Journal of Medicine, 350, 1937-1944.

https://doi.org/10.1056/NEJMoa032646

[12] Bernier, J., Domenge, C., Ozsahin, M., Matuszewska, K., Lefèbvre, J.L., Greiner, R.H., Giralt, J., Maingon, P., Rolland, F., Bolla, M., Cognetti, F., Bourhis, J., Kirkpatrick, A. and van Glabbeke, M. (2004, May 6) Postoperative Irradiation with or without Concomitant Chemotherapy for Locally Advanced Head and Neck Cancer. The New England Journal of Medicine, 350, 1945-1952. https://doi.org/10.1056/NEJMoa032641

[13] Dimery, I.W., Legha, S.S., Shirinian, M. and Hong, W.K. (1990, June) Fluorouracil, Doxorubicin, Cyclophosphamide, and Cisplatin Combination Chemotherapy in Advanced or Recurrent Salivary Gland Carcinoma. Journal of Clinical Oncology, 8, 1056-1062. https://doi.org/10.1200/JCO.1990.8.6.1056

[14] Schoenfeld, J.D., Sher, D.J., Norris, C.M., Haddad, R.I., Posner, M.R., Balboni, T.A. and Tishler, R.B. (2012) Salivary Gland Tumors Treated with Adjuvant Intensity-Modulated Radiotherapy with or without Concurrent Chemotherapy. International Journal of Radiation Oncology, Biology, Physics, 82, 308-314.

https://doi.org/10.1016/j.ijrobp.2010.09.042 
[15] Tanvetyanon, T., Qin, D., Padhya, T., et al. (2009) Outcomes of Postoperative Concurrent Chemoradiotherapy for Locally Advanced Major Salivary Gland Carcinoma. Archives of Otolaryngology_Head and Neck Surgery, 135, 687-692. https://doi.org/10.1001/archoto.2009.70

[16] Mourad, M., Jetmore, T., Jategaonkar, A.A., Moubayed, S., Moshier, E. and Urken, M.L. (2017) Epidemiological Trends of Head and Neck Cancer in the United States: A SEER Population Study. Journal of Oral and Maxillofacial Surgery, 75, 2562-2572. https://doi.org/10.1016/j.joms.2017.05.008

[17] Fu, K.K., Leibel, S.A., Levine, M.L., Friedlander, L.M., Boles, R. and Phillips, T.L. (1977) Carcinoma of the Major and Minor Salivary Glands: Analysis of Treatment Results and Sites and Causes of Failures. Cancer, 40, 2882-2890.

https://doi.org/10.1002/1097-0142(197712)40:6<2882::AID-CNCR2820400618>3.0. $\underline{\mathrm{CO} ; 2-\mathrm{I}}$ 